\title{
IMPACTOS DA PANDEMIA DE CORONAVÍRUS EM UM CAPS INFANTOJUVENIL DO DISTRITO FEDERAL
}

\section{THE CORONAVIRUS PANDEMIC IMPACT ON A CHILD AND ADOLESCENT CAPS OF THE FEDERAL DISTRICT}

\author{
Amanda Teixeira Brandão ${ }^{1}$ \\ Clara Correa Lima ${ }^{2}$ \\ Gabrielle Silva Mesquita ${ }^{3}$ \\ Wilson Dias da Costa ${ }^{4}$
}

1 - Assistente Social residente em Saúde Mental Infantojuvenil, Escola Superior de Ciências

da Saúde - ESCS/FEPECS. E-mail: amanda.brandao02@gmail.com

2- Psicóloga residente em Saúde Mental Infantojuvenil, Escola Superior de Ciências da Saúde

- ESCS/FEPECS. E-mail: claracorrealima@gmail.com

3- Terapeuta Ocupacional residente em Saúde Mental Infantojuvenil, Escola Superior de

Ciências da Saúde - ESCS/FEPECS. E-mail: gabrielle.s.mesquita@gmail.com

4 - Enfermeiro preceptor em Saúde Mental Infantojuvenil e servidor do CAPSi Sobradinho SES/DF. E-mail: nosliwsaid @ gmail.com

Sobradinho/DF, abril de 2020. 


\title{
RESUMO
}

A atual pandemia de Coronavírus (COVID-19), originária da China, tem se alastrado por diversos continentes. O primeiro caso confirmado no Brasil foi registrado em 26 de fevereiro de 2020, no estado de São Paulo. Em 07 de março de 2020, o Ministério da Saúde confirmou o primeiro caso de COVID-19 no Distrito Federal. Com a escalada de novos casos no Brasil, decretos governamentais suspenderam o funcionamento de escolas e outros diversos estabelecimentos na tentativa de conter o avanço da pandemia. Atendendo às recomendações de se evitar a aglomeração de pessoas, os atendimentos em grupo nos estabelecimentos de saúde também foram suspensos. Com o impacto das medidas adotadas e recomendações para o distanciamento social, observou-se importante diminuição no fluxo de pacientes no Centro de Atenção Psicossocial Infantojuvenil de Sobradinho, que atende crianças e adolescentes com transtornos mentais e quadro de sofrimento psíquico grave. A proposta deste trabalho, de natureza quali-quantitativa, é apresentar dados sobre frequência de atendimentos psiquiátricos e acolhimentos do tipo "porta aberta", bem como discorrer acerca de possíveis causas para o esvaziamento da unidade, obstáculos enfrentados e perspectivas quanto ao retorno das atividades pós-pandemia.

Palavras-chave: COVID-19; Coronavírus; Saúde Mental; Saúde Mental Infantojuvenil; CAPSi.

\begin{abstract}
The current Coronavirus (COVID-19) pandemic, originating in China, has spread to several continents. The first confirmed case in Brazil was registered on February 26, 2020, in the state of São Paulo. On March 7, 2020, the Ministry of Health confirmed the first case of COVID-19 in the Federal District. With the escalation of new cases in Brazil, the governor of the Federal District issued decrees suspending the operation of schools and other establishments in an attempt to contain the advance of the pandemic. In view of the recommendations to avoid social crowding, group care in health facilities was also suspended. With the impact of the adopted measures and the recommendations for social distancing, there was an important decrease in the flow of patients in the Child and Adolescent Psychosocial Care Center in Sobradinho, which serves children and adolescents with mental disorders and severe psychological distress. The purpose of this work, which has a qualitative and quantitative nature, is to present data on the frequency of psychiatric care and 'open door care', as well as to discuss the possible causes for a lack of attendance within the unit, and the obstacles faced and the perspectives regarding the return of post-pandemic activities.
\end{abstract}

Key-words: COVID-19; Coronavirus; Mental Health; Child and Adolescent Mental Health; CAPSi. 


\section{INTRODUÇÃO}

Nem sempre é uma tarefa fácil se organizar diante de fatores inesperados no cotidiano, o que ocasiona diversas manifestações de frustração. Para viver com qualidade e saúde, muitas vezes é exigido do indivíduo agir com maleabilidade e criatividade, de forma a visualizar alternativas para resolução dos mais variados problemas. Sendo assim, a saúde é promovida de acordo com as práticas cotidianas de uma pessoa e de como são seus hábitos, trazendo implicações no futuro conforme ocupou seu tempo e espaço em meio à sociedade. Quando a vida em comunidade é afetada, o cotidiano do indivíduo também é atingido e fragilizado, e as suas atividades podem tornar-se empobrecidas ${ }^{1,2}$.

A atual situação da pandemia de coronavírus traz desafios sem precedentes em níveis coletivos e individuais, que mudam a depender da cultura, contexto social, recursos materiais e psíquicos de cada grupo e pessoa. A saúde mental da população fica em risco no momento de crise que vivemos, sendo um desafio para os serviços especializados gerir essa demanda, uma vez que os mesmos também sofrem com os impactos das medidas de distanciamento social e todas as outras contingências da pandemia.

Os coronavírus são vírus RNA com grande disseminação entre humanos, aves e mamíferos e tem o reconhecimento da comunidade científica desde 1937. Eles pertencem à subfamília Coronavirinae da família Coronaviridae, ordem Nidovirales. Dentro desta categoria estão os vírus responsáveis por resfriados leves, mas também por doenças respiratórias graves, como a Síndrome Respiratória Aguda Grave (SARS) e a Síndrome Respiratória do Oriente Médio (MERS). A doença nomeada como COVID-19 tem como agente o novo coronavírus (SARS-CoV-2), uma evolução genética do vírus causador do surto de SARS no início do século XXI.

O Ministério da Saúde elenca como principais sintomas da COVID-19 a presença de febre acima de $37,8^{\circ} \mathrm{C}$, tosse e dificuldade de respirar. A doença também pode apresentar outros 
sintomas menos comuns, como: cansaço, dores no corpo, mal estar em geral, congestão nasal, corrimento nasal, dor de garganta ou dor no peito. É também possível que algumas pessoas possam ser infectadas e não apresentarem sintomas. Cerca de $80 \%$ das pessoas com a doença se recuperam sem necessidade de tratamento hospitalar, sendo indicado apenas repouso, ingestão de líquidos e medicamentos para alívio dos sintomas. No entanto, 1 em cada 6 pessoas podem desenvolver um quadro grave (com pneumonia e insuficiência respiratória) e precisar de suplemento de oxigênio e ventilação mecânica, por isso a importância de procurar assistência médica em caso de falta de $\operatorname{ar}^{3}$. O grupo de risco, que possui a maior chance de evoluir a doença em seu estado grave, é composto por pessoas idosas e portadores de condições crônicas, tais como pressão alta, doenças cardiovasculares e diabetes.

O Ministério da Saúde elenca as principais formas de contágio: gotículas de saliva, espirro, tosse, catarro, contato pessoal próximo (com toque ou aperto de mão), contato com objetos ou superfícies contaminadas seguido de contato com a boca, nariz ou olhos. A transmissão pode ocorrer por meio de gotículas respiratórias ou contato próximo (menos de 1 metro) com quem possui sintomas respiratórios. No Brasil, ainda não há nenhuma evidência que indique que animais possam ser a fonte de transmissão do vírus ${ }^{4}$. A Organização Mundial da Saúde (OMS) afirma que o vírus é capaz de sobreviver em superfícies, por isso faz-se necessário a correta higienização das mãos após entrar em contato com superfícies e objetos usados por diversas pessoas.

O período de incubação (tempo transcorrido entre a infecção e o aparecimento dos primeiros sintomas) é de 2 a 14 dias $^{5}$, sendo que, na maioria dos casos, o tempo médio é de 5 dias (entre 4,1 e 7 dias para 95\% dos casos) ${ }^{6}$. Existem observações preliminares que indicam a possibilidade de transmissão viral em pacientes assintomáticos ${ }^{7}$. No entanto, mesmo que isso aconteça, a transmissão é menos frequente. Isso se dá porque a excreção do vírus está associada a sintomatologia, ou seja, quanto mais carga viral, mais sintomas e mais transmissão. Em 
posicionamento oficial, a OMS entende que a transmissão de pessoas assintomáticas pode ocorrer, mas é rara, não sendo a fonte majoritária de transmissão ${ }^{8}$.

O primeiro registro da COVID-19 em humanos foi datado em 31 de dezembro de 2019 em Wuhan, China. Em março de 2020, já havia 118 mil casos notificados ao redor do mundo e 4.300 mortes registradas $^{9}$; no dia 11 deste mesmo mês a OMS decretou a situação como uma pandemia mundial. Até 23 de abril de 2020, a COVID-19 atingiu mais de 200 territórios em todo globo, contabilizando 2.637.681 casos confirmados e 184.220 mortes (PODER 360). Diferentes estratégias estão sendo tomadas por chefes de estado e autoridades dos países afetados pela doença, dentre elas: a testagem da população, distanciamento social, fechamento de escolas, comércio e fronteiras.

A pandemia da COVID-19 está gerando uma grande crise nos sistemas de saúde de diversos países; um dos principais motivos é a elevada transmissibilidade da doença que ocasiona um alto número de quadros graves ao mesmo tempo, gerando a superlotação dos leitos das unidades de tratamento intensivo (UTIs). A pandemia ameaça e gera agravos não somente aos infectados pela doença e suas famílias, mas também a todos que não adoeceram por conta do vírus. Os impactos decorrentes das medidas para contenção do vírus atingem toda a sociedade, ocasionando o colapso do sistema de saúde, elevação do número de casos de violência doméstica, aumento na taxa de desemprego e a diminuição dos PIBs. As pessoas mais vulneráveis aos impactos da pandemia são aquelas que fazem parte de grupos que já sofrem violações de direitos constantes em seus cotidianos.

No Brasil, a situação da pandemia é alarmante: até o dia 23 de abril de 2020 o número de infectados ultrapassava 45 mil $^{10}$. É necessário ressaltar que tais números não são totalmente reais: há uma tendência de subnotificações dos casos, principalmente daqueles leves ${ }^{6}$, o que é agravado pela falta de testagens no país. Em fevereiro de 2020, o Ministério da Saúde declarou Emergência de Saúde Pública de Importância Nacional (ESPIN), sendo este o nível de alerta 
mais elevado de acordo com a classificação de risco em três níveis (Alerta, Perigo Iminente e Emergência em Saúde Pública). Ainda no mês de fevereiro, no âmbito do Distrito Federal, a Secretaria de Estado de Saúde do Distrito Federal (SES/DF) desenvolveu um Plano de Contingência para sistematizar as ações e procedimentos para o enfrentamento deste quadro ${ }^{11}$.

No mês de março, o governador Ibaneis Rocha assinou decretos e anunciou um pacote de medidas para o combate ao coronavírus ${ }^{12}$ que determinavam as seguintes ações: suspensão das aulas em instituições públicas e privadas, suspensão de eventos com público maior a cem pessoas, suspensão das atividades de cinemas e teatros, fechamento de academias, aferição de temperatura de passageiros no aeroporto e rodoviária interestadual, realização de exames compulsórios em pacientes com suspeita da doença, mudança no atendimento de órgãos públicos, suspensão das visitas em presídios, suspensão do atendimento ao público em shopping center, feiras populares e clubes recreativos, fechamento do zoológico, parques recreativos e urbanos, boates e casas noturnas e adoção de ponto facultativo para servidores do DF, com exceção das áreas de segurança, vigilância sanitária e saúde. Neste contexto, encontram-se os dispositivos de CAPS, que apesar de não atuarem diretamente nas demandas clínicas relacionadas a COVID-19, possuem extrema importância no atendimento aos agravos de saúde mental.

A respeito da COVID-19, em nota publicada em 18 de março de 2020, a SES/DF realizou uma atualização do plano de contingência Coronavírus/COVID-19 incluindo os Serviços Especializados de Saúde Mental ${ }^{13}$. Foi orientado que, no âmbito infantojuvenil, permanecessem abertos os CAPSis, além do Centro de Orientação Médico Psicopedagógica (COMPP) e Adolescentro, seguindo apenas com o atendimento na modalidade individual, ficando a cargo do gestor local a redistribuição dos servidores, conforme a necessidade. Em um momento de calamidade pública, os dispositivos de saúde mental ainda são necessários para atendimentos de emergência, acompanhamento de casos graves e/ou recém-acolhidos. Para 
isso, nos serviços de saúde mental passaram a ser feitas triagens dos pacientes, de forma a identificar a presença de usuários com sintomas respiratórios, fazer a utilização correta dos equipamentos de proteção individual (EPIs) e evitar a transmissão da doença.

O Centro de Atenção Psicossocial Infantojuvenil (CAPSi) é um recurso de saúde mental vinculado à SES/DF, que atende crianças e adolescentes menores de 18 anos de idade em sofrimento psíquico grave e menores de 16 anos de idade que fazem uso de álcool e/ou outras drogas ${ }^{14}$. O serviço tem como objetivo realizar atendimento humanizado e em liberdade, como preconizado na lei $\mathrm{n}^{\mathrm{o}} 10.216^{15}$, que redirecionou o modelo assistencial em saúde mental, se opondo ao cenário manicomial vigente até 2001, ano de promulgação da lei antimanicomial.

O CAPSi Sobradinho funciona de segunda à sexta-feira e conta com equipe multiprofissional incluindo médicos, psicólogas, assistente social, enfermeiros, técnicas de enfermagem, fonoaudióloga e terapeuta ocupacional. Recebe diariamente usuários encaminhados por diversos serviços, tais como outros estabelecimentos de saúde, escolas, conselhos tutelares e também demandas espontâneas. O centro atua com acolhimento porta aberta, atendimentos multiprofissionais em grupos e atendimentos individuais, focados não apenas nas crianças e adolescentes, mas também em seus familiares e/ou responsáveis. Há pouco menos de um ano, o serviço também é cenário do Programa de Residência Multiprofissional em Saúde Mental Infantojuvenil, contando então com o trabalho de residentes de diversas áreas profissionais. Os autores deste artigo fazem parte do referido programa e a experiência relatada se deu durante o período de atuação das residentes na unidade.

Por atuar diretamente na saúde mental da população, o trabalho do CAPSi, além de lidar com diagnósticos e transtornos, é constantemente interligado a questões que perpassam a sociedade em grande e pequena escala, tais como: nível de desigualdade social, registro de violências, falta de acesso à serviços de saúde, de renda e de lazer, entre outros fatores que influenciam no bem estar psíquico e emocional dos usuários. Dentre essas questões, é possível 
mencionar o que atualmente vem se tornando o destaque de notícias, preocupações e interferências no cotidiano da sociedade: a COVID-19, ou coronavírus.

Entendendo que se trata de uma pandemia, as suas consequências têm impactado em todos os níveis de serviço de saúde da população. A partir do recorte sobre a unidade, será possível analisar a seguir algumas consequências diretas nos atendimentos do CAPSi e seus usuários, considerando que houve a suspensão das atividades em grupo, porém a manutenção de todas as modalidades de atendimentos individuais. Para tanto, foram analisados dois critérios: os atendimentos porta aberta e os atendimentos médicos psiquiátricos.

\section{COMPARATIVO DO NÚMERO DE ATENDIMENTOS PORTA ABERTA ANTES E}

\section{APÓS A PANDEMIA}

A partir da análise do livro de registros de entrada de pacientes do CAPSi Sobradinho, verificou-se que, no período de 14 de Março a 15 de Abril de 2020, em que as medidas de distanciamento e restrição de movimentação da população começaram a ser adotadas no Distrito Federal, o número de usuários que procuraram a unidade para acolhimento do tipo "porta aberta", ou seja, casos novos, sem necessidade de agendamento prévio, foi de apenas 15, em 22 dias úteis, estabelecendo uma média de 0,68 usuários por dia. Analisando o período anterior à pandemia, compreendido entre 01 de Fevereiro a 13 de Março de 2020, foram 102 acolhimentos porta aberta, em 27 dias úteis, estabelecendo uma média de 3,77 usuários por dia. Para estabelecer uma comparação temporal, considerando períodos de final de férias ou início do ano letivo escolar, também foram analisados os registros referentes aos mesmos períodos do ano de 2019. Foi verificado que, entre 14 de Março e 15 de Abril de 2019, foram 101 atendimentos porta aberta, em 23 dias úteis, estabelecendo uma média de 4,39 por dia. Entre 01 de Fevereiro e 13 de Março, foram 79 atendimentos porta aberta, em 26 dias, estabelecendo média de 3,03 usuários por dia. Desta forma, no período em que se iniciaram as medidas de 
restrição às aglomerações e movimentação de pessoas, observou-se uma queda significativa no número de usuários que procuraram a unidade para um primeiro atendimento, principalmente se comparado ao mesmo período do ano de 2019. Os números apresentados também estão demonstrados no gráfico abaixo:

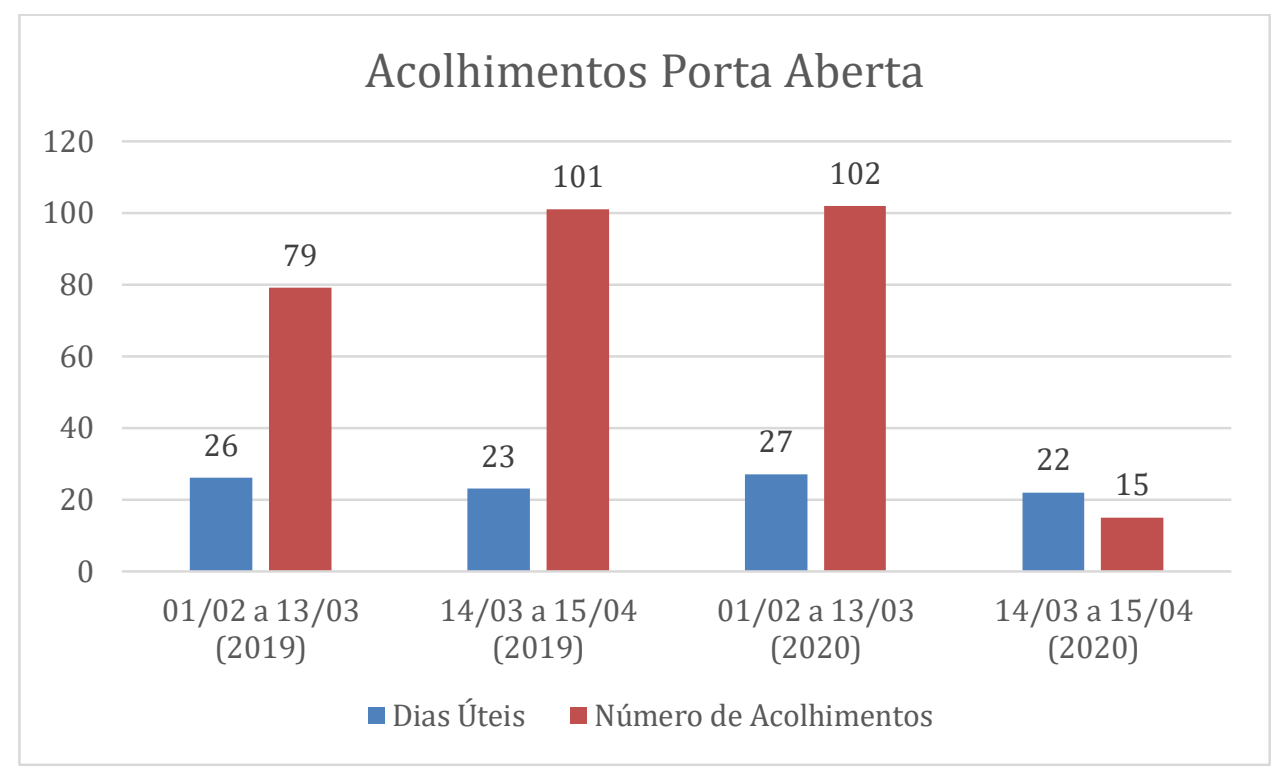

\section{COMPARATIVO DO NÚMERO DE ATENDIMENTOS DA PSIQUIATRIA ANTES E}

\section{APÓS A PANDEMIA}

Outros dados que foram possíveis de ser coletados de forma fidedigna e acessível referem-se à presença dos usuários às consultas com o psiquiatra da equipe, pois o agendamento é feito online pelo Google Agenda e em todas as consultas o próprio psiquiatra faz o controle de presença ou falta dos usuários. Desta forma, verificou-se que, entre 01 de Fevereiro e 13 de Março de 2019, foram agendadas 70 consultas, sendo que destas, 7 usuários não compareceram, ou seja, um percentual de $10 \%$ de faltas. No período entre 14 de Março e 15 de Abril de 2019, foram 84 consultas agendadas, sendo que 8 usuários não compareceram, estabelecendo o percentual de 9,52\% de faltas. Já em 2020, entre 01 de Fevereiro e 13 de Março, das 114 consultas agendadas, foram contabilizadas 20 faltas, ou seja, um percentual de $17,54 \%$. No período de maior impacto relacionado à pandemia de coronavírus, entre 14 de Março a 15 de 
Abril, das 99 consultas agendadas, 25 usuários faltaram, estabelecendo percentual de 25,25\% de faltas. Os dados coletados estão descritos no gráfico abaixo:

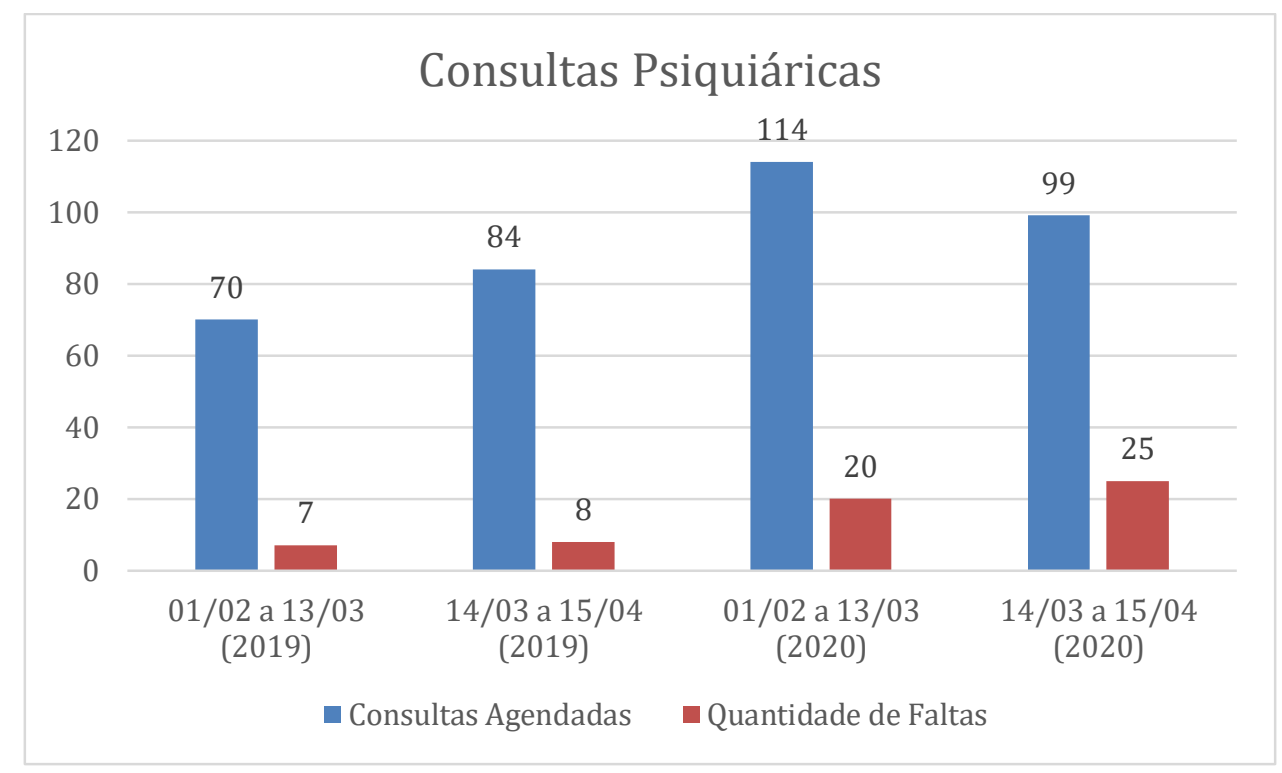

Vale destacar o aumento no número de agendamentos em 2020, se comparado a 2019, justificado pelo fato de que o referido profissional no período de 2019 possuía vínculo empregatício de $20 \mathrm{hs}$ semanais, enquanto que no presente ano trabalha 40hs semanais.

Os atendimentos agendados para outros profissionais da equipe, incluindo continuações de acolhimento, atendimentos individuais e revisões de planos terapêuticos, são registrados em agenda física, em que consta a distribuição diária de toda equipe. Entretanto, os profissionais nem sempre anotam na referida agenda se o usuário compareceu ou não à unidade. Desta forma, considerando circunstâncias relacionadas ao serviço, não seria possível a obtenção de dados confiáveis. Entretanto, mesmo sem a obtenção destes dados, todos os profissionais da equipe relataram elevado percentual de faltas dos usuários agendados.

\section{MOTIVOS DA EVASÃO E SUAS CONSEQUÊNCIAS NO CAPSi}

Partindo da percepção dos profissionais da equipe e do que se pôde observar em relação aos impactos da pandemia de uma maneira geral na sociedade, este estudo procurou estabelecer as principais causas para o esvaziamento da unidade e o aumento no número de faltas aos 
atendimentos. Neste sentido, a principal explicação seria referente às recomendações veiculadas em diversas mídias sobre o distanciamento social que, a princípio, geraram um bom nível de compreensão e temor nas pessoas em sair de casa, a não ser para trabalhar ou em situações de extrema necessidade. Sendo assim, em relação a casos de usuários até então estáveis do ponto de vista psíquico e emocional, observou-se grande número de faltas, relacionadas a continuações de acolhimento e atendimentos individuais previamente agendados.

Da mesma forma, imagina-se que aqueles usuários encaminhados e na pretensão de procurarem o CAPSi para acolhimento porta aberta, exceto em situações de gravidade extrema, optaram por aguardar outro momento para buscar atendimento. Outro fator, percebido na fala de alguns usuários, foi a dificuldade de estabelecer um canal de comunicação com o serviço, pois o telefone funcional encontrava-se indisponível devido à situação recente de curto-circuito na rede elétrica. Muitos usuários relataram, inclusive, que acreditavam que o serviço não estivesse funcionando.

Além dos motivos já explicitados, foi mencionada também a dificuldade de locomoção de casa até o CAPSi, já que boa parte dos usuários do serviço utilizam o benefício de Passe Livre Estudantil que, em período de suspensão das aulas escolares, encontrava-se bloqueado para uso, conforme decreto $40.520^{16}$, de 14 de março de 2020, dificultando o acesso aos serviços.

Em relação às consultas psiquiátricas, apesar de ter sido verificado um percentual maior de faltas em relação ao habitual, o impacto não foi tão expressivo em relação aos atendimentos dos outros profissionais. Tudo indica que a necessidade da prescrição e/ou renovação de receitas medicamentosas seja um dos fatores. Além disso, o entendimento hegemônico do médico como maior detentor do saber faz com que a maioria dos usuários valorizem mais as consultas médicas, em detrimento dos atendimentos com os demais profissionais, por mais que a equipe em sua prática diária reforce a importância do acompanhamento multiprofissional. 
Para além da visão biomédica do cuidado, o alto número de atendimentos psiquiátricos em comparação aos acolhimentos porta aberta também pode sugerir que, ainda assim, existe a demanda de atenção à saúde mental em período de pandemia. A situação de alarde, excesso de informação, isolamento social e mudanças de rotina são consequências da COVID-19, responsáveis por elevação dos níveis de preocupação e ansiedade nos usuários.

A respeito das consequências decorrentes da pandemia, foi percebido pelos profissionais, durante atendimento, que o distanciamento social teve forte impacto no cotidiano e nas relações interpessoais dos usuários do CAPSi Sobradinho. Foi observado o aumento dos sentimentos de tédio, desamparo, irritabilidade, solidão e tristeza, além da presença do medo de adoecer, de morrer ou de perder entes queridos e de ser excluído se contrair a doença. Observou-se que, em algumas famílias, todos os membros puderam se manter em suas residências, enquanto que em outras alguns membros continuavam tendo que sair de casa para trabalhar, vivenciando ao mesmo tempo o medo de perder o emprego e/ou o peso de ser vetor da doença.

Os usuários do serviço relataram estresse, desorganização da rotina com alterações de alimentação, de sono e aumento de ansiedade. Sendo assim, houve ruptura de atividades significativas para os indivíduos e mudanças em seus papéis ocupacionais ${ }^{2,17,18}$. A realização de atividades físicas, utilizadas como recurso de saúde mental, também ficou prejudicada. Devido ao fechamento de centros esportivos e a proibição de aglomeração de pessoas, os exercícios físicos precisaram ser adaptados para práticas individuais no próprio domicílio. Quanto à dinâmica familiar, genitores e/ou responsáveis também afirmaram perceber mudanças de comportamento nas crianças e adolescentes, se mostrando mais ansiosos e agitados por permanecerem durante a maior parte do dia apenas em suas casas e com reduzidas formas de socialização. 
Outra questão bastante presente foi o grande impacto acarretado na renda das famílias por conta das restrições de funcionamento de estabelecimentos, que desencadearam outras imensas vulnerabilidades sociais. O Centro de Referência de Assistência Social (CRAS) que atua diretamente nas situações de proteção social, teve seus atendimentos reduzidos a teleatendimentos ${ }^{19}$, dificultando ainda mais o acesso dos usuários aos seus serviços. Entendendo que grande parte da população usuária do CAPSi encontra-se em situação de vulnerabilidade econômica e muitas vezes necessita do atendimento do CRAS, foi relatado durante período de pandemia a presença de insegurança alimentar e habitacional por falta de recursos para compra de alimentos e pagamentos de aluguéis para moradia.

O esvaziamento do serviço também trouxe dificuldades para as residentes multiprofissionais presentes na unidade, assim como para os demais residentes do programa que estão atuando em outros cenários, já que não foi possível para os mesmos conhecerem os grupos, a dinâmica e demandas habituais do serviço. O contexto atual traz desafios inéditos, considerando que o referido programa tem duração de dois anos, sendo que durante o primeiro ano os residentes rodiziam pelo período máximo de 3 meses por diversos cenários de aprendizagem e permanecem todo segundo ano em apenas um, onde desenvolvem o trabalho de conclusão de curso. Em meio a este contexto, os residentes enfrentam outras angústias relacionadas à pouca experiência profissional, fase de adaptação, conhecimento de normas, avaliações e toda estrutura do programa. Enfrentam ainda o medo do desconhecido, de se afastarem de suas famílias e de se contaminar no deslocamento até o cenário, levando em conta que grande parte utiliza o transporte coletivo.

Os sentimentos e angústias enfrentados pelos residentes também puderam ser observados na fala dos profissionais do serviço. As medidas de restrição de movimentação adotadas pelos governantes abriram a possibilidade para diversas categorias profissionais adotarem ações como a liberação de funcionários e férias coletivas. Entretanto, para os 
profissionais de saúde, a pandemia resultou no cancelamento de férias, abonos e outros afastamentos previstos em lei. Muitos tiveram que readequar suas rotinas, especialmente relacionadas à família e filhos, considerando que os estabelecimentos de ensino fecharam por tempo indeterminado.

Entretanto, a pandemia e consequente esvaziamento do serviço possibilitou que a unidade passasse por reforma, com troca de toda rede elétrica, tendo em vista que o imóvel, no formato semelhante a uma casa, já é bastante antigo e, antes de ser habilitado como CAPSi, já havia funcionado como outros órgãos, sem nunca ter passado por grande reforma. Uma reforma dessa magnitude seria inviável de acontecer em momento de pleno funcionamento da unidade. Outro aspecto positivo foi a possibilidade da equipe ter maior tempo disponível para a realização de práticas voltadas ao cuidado e valorização do servidor, por meio de dinâmicas, atividades lúdicas, rodas de conversa, com o intuito de amenizar a tensão relacionada aos impactos da pandemia.

\section{CONCLUSÃO}

A pandemia de coronavírus desencadeou impactos na saúde de milhões de pessoas distribuídas em todo planeta, que neste período de 2020 tiveram que se reorganizar em questão de rotinas, se adaptar a novos manejos de saúde e manter um drástico distanciamento social para garantir melhores probabilidades de sucesso no combate ao vírus. No Brasil, os casos se iniciaram posteriormente aos países mais afetados, mas ainda seguindo semelhantes critérios de precaução e controle epidemiológico.

Mesmo com as medidas restritivas, diversos dispositivos de saúde permaneceram em funcionamento no período de pandemia, incluindo aqueles direcionados à atenção a saúde mental. Os CAPS são importantes atores na estratégia de combate a pandemia, uma vez que, 
sendo um dos ordenadores da Rede de Atenção Psicossocial (RAPS), conseguem mapear consequências negativas das medidas de enfrentamento da doença e prevenir violações de direitos. No caso específico do público-alvo dos CAPSis, sabemos que, a partir da promulgação da lei $\mathrm{n}^{\mathrm{o}} 8.069^{20}$ - que dispõe sobre o Estatuto da Criança e do Adolescente (ECA) - os direitos de crianças e adolescentes têm máxima preferência e, por isso, a garantia destes por parte do poder público deve ser incluída como uma das medidas de combate à pandemia.

Acerca de dados apresentados a respeito de atendimentos psiquiátricos e acolhimentos do CAPSi Sobradinho no comparativo de 2019 e 2020, ficou evidente que a pandemia diminuiu bruscamente a procura por livre demanda ao serviço. Os motivos dessa queda puderam se apresentar nas mais diversas áreas, porém sendo a grande maioria relacionada a falta de locomoção, falta de comunicação por meios telefônicos e o próprio cumprimento da medida de distanciamento social imposta pelo governo do Distrito Federal.

No aspecto psicossocial, as medidas adotadas podem resultar a longo prazo em uma maior incidência de Transtornos Depressivos e de Ansiedade, além de Transtorno Obsessivo Compulsivo (TOC). Também podem interferir nas atividades físicas de atenção à saúde, gerar alterações no funcionamento do corpo e mente mediante alterações de rotina, assim como expor crianças e adolescentes à situações de vulnerabilidade e violência, seja ela física, psicológica, sexual ou autoprovocada, visto que a maioria desses episódios acontecem dentro das próprias residências $^{21}$, onde se encontram a maior parte dos dias e, além disso, nos casos de violência intrafamiliar, o medo das consequências geradas pela denúncia pode estar presente. Ainda não é possível avaliar os impactos pós pandemia, uma vez que números exatos só poderão ser analisados com precisão em momento posterior à crise. No entanto, desde já, torna-se fundamental o olhar profissional atento a essas questões e a preparação para coleta de dados reais. Segundo autores ${ }^{17,21}$, o prognóstico esperado é que, a partir do retorno às atividades habituais, seja observado aumento da procura ao serviço de saúde mental. 
Como resposta aos impactos sofridos pelos usuários, bem como pelos profissionais e residentes em serviço, é indicado como medida de promoção de saúde o exercício do autocuidado e autocompaixão ${ }^{22,23}$ frente a tantas mudanças e novos desafios. Além disso, é importante buscar estratégias de bem estar, identificar gatilhos que trazem sofrimento, manter contato com a rede de apoio (ainda que por meio virtual) e valorizar a prática de exercícios físicos e de alívio do estresse. Com o grande tempo de permanência em casa, é importante saber conciliar horários de lazer, trabalho ou estudo. Em meio à enxurrada de notícias, é fundamental procurar sempre fontes de confiança e evitar se expor excessivamente à informações da mídia relacionadas à pandemia. Caso sinta necessidade de maior acompanhamento direcionado à saúde mental, é recomendada a procura direta de serviço especializado.

Portanto, é essencial que o serviço elabore, em períodos de crise, estratégias para monitoramento dos casos por meio de busca ativa via telefone e, se necessário, marcação de atendimentos individuais. Isso possibilita uma maior proximidade com os pacientes e proporciona alternativas de acesso ao serviço, mantendo as atuações de saúde mental e prevenção de situações de vulnerabilidades ${ }^{17,18}$. Outra questão a ser levantada é a provocação às autoridades quanto à precariedade da infraestrutura e acessibilidade do usuário ao serviço, necessárias ao atendimento de crianças e adolescentes. A ausência de tais condições prejudica a qualidade da assistência em saúde, que deveria ser garantida com preferência, segundo a própria legislação do país. 


\section{REFERÊNCIAS BIBLIOGRÁFICAS}

1. Galheigo SM. O cotidiano na terapia ocupacional: cultura, subjetividade e contexto histórico-social. Revista de Terapia Ocupacional da Universidade de São Paulo, v. 14, n. 3, p. 104-109, 2003.

2. Mesquita GS. Gestos cotidianos na produção de vida e saúde. Brasília, 2019.

3. Sociedade Brasileira de Infectologia (SBI). Informe da sociedade brasileira de infectologia sobre o novo coronavírus $\mathbf{n}^{\circ} 10$ - perguntas e respostas para profissionais da saúde e para publico em geral. Disponível em https://www.infectologia.org.br/admin/zcloud/125/2020/03/a10bbe8ddf9cde769147d6 0d71b6167070428492465e82ee96bdf67f8d20a011.pdf

4. Fundação Oswaldo Cruz (FIOCRUZ). COVID-19 - Perguntas e Respostas. Disponível em: https://portal.fiocruz.br/coronavirus-perguntas-e-respostas. 
5. Ministério da Saúde. Coronavírus (COVID-19). Disponível em: https://coronavirus.saude.gov.br/.

6. Sociedade Brasileira De Pediatria (SBP). Departamento Científico de Infectologia. Novo Coronavírus (COVID-19). Disponível em: https://www.sbp.com.br/fileadmin/user upload/22340d-DocCientifico _Novo_coronavirus.pdf

7. Rothe $\mathrm{C}$, et al. Transmission of 2019-nCoV infection from an asymptomatic contact in Germany. The New England Journal of Medicine, 2020. DOI: 10.1056/NEJMc2001468

8. World Health Organization (WHO). Novel Coronavirus $(2019-\mathbf{n C o V})-$ Situation Report - 12. Disponível em: https://www.who.int/docs/defaultsource/coronaviruse/situation-reports/20200201-sitrep-12ncov.pdf?sfvrsn=273c5d35_2.

9. OMS decreta pandemia mundial por novo coronavírus. Extra; 2020 Mar 11. Disponível em: https://extra.globo.com/noticias/saude-e-ciencia/oms-decretapandemia-mundial-por-novo-coronavirus-24298659.html

10. Conheça os números atualizados da covid-19 no Brasil e no mundo. Poder 360; 2020 Apr 23. Disponível em: https://www.poder360.com.br/coronavirus/conheca-osnumeros-atualizados-da-covid-19-no-brasil-e-no-mundo-3/

11. Secretaria de Estado de Saúde do Distrito Federal (SES/DF). Plano de Contingência para Epidemia da Doença pelo Coronavírus 2019 (COVID-19) do Distrito Federal (versão 4). Brasília, 2020. Disponível em: https://agenciabrasilia.df.gov.br/wpconteudo/uploads/2020/03/Plano-de-Continge\%CC\%82ncia-Coronavirus16.03.2020.pdf.pdf.pdf.pdf 
12. Pacote de medidas para combater o coronavírus. Agência Brasília; 2020 Mar 13. Disponível em: https://www.agenciabrasilia.df.gov.br/2020/03/13/pacote-de-medidaspara-combater-o-coronavirus/

13. Secretaria de Estado de Saúde do Distrito Federal (SES/DF). Circular no 15/2020 SES/SAA. Atualização do Plano de Contingência para Epidemia da Doença pelo Coronavírus 2019 (COVID-19) do Distrito Federal (versão 5). Brasília, 2020.

14. Secretaria de Estado de Saúde do Distrito Federal (SES/DF). CAPSi - Centro de Atenção Psicossocial Infantil de Sobradinho. Disponível em http://www.saude.df.gov.br/capsi-sobradinho/.

15. Brasil. Lei $N^{0} 10.216$, de 6 de abril de 2001. Dispõe sobre a proteção e os direitos das pessoas portadoras de transtornos mentais e redireciona o modelo assistencial em saúde mental. Diário Oficial da União 2001; 9 abr.

16. Distrito Federal. Decreto 40.520, de 14 de março de 2020. As medidas para enfrentamento da emergência de saúde pública de importância internacional decorrente do novo coronavírus. Diário Oficial do DF 2020; 14 mar.

17. Ornell F, et al. "Pandemic fear" and COVID-19: Mental health burden and strategies. Brazilian Journal of Psychiatry.

18. Salles MM, Matsukura TS. Estudo de revisão sistemática sobre o uso do conceito de cotidiano no campo da Terapia Ocupacional na literatura de língua inglesa. Cadernos Brasileiros de Terapia Ocupacional, v. 23, n. 1, 2015.

19. Serviços de assistência social implantam atendimento via telefone. Correio Braziliense; $2020 \quad$ Mar $16 . \quad$ Disponível em: <https://www.correiobraziliense.com.br/app/noticia/cidades/2020/03/26/interna_cidad $\underline{\text { esdf,840546/servicos-de-assistencia-social-implantam-atendimento-via- }}$ telefone.shtml>. 
20. Brasil. Lei No 8.069, de 13 de julho de 1990. Dispõe sobre o Estatuto da Criança e do Adolescente e dá outras providências. Diário Oficial da União 1990; 16 jul.

21. Secretaria de Estado de Saúde do Distrito Federal (SES/DF). Informe Epidemiológico Anual de Violência Interpessoal e Autoprovocada no Distrito Federal. Brasília, 2020.

22. Neff K. Autocompaixão - pare de se torturar e deixe a insegurança para trás. 2017.

23. Santos IIV, Cunha M. Auto-compaixão: a sua relação com os estados emocionais negativos. Brasília, 2012. 